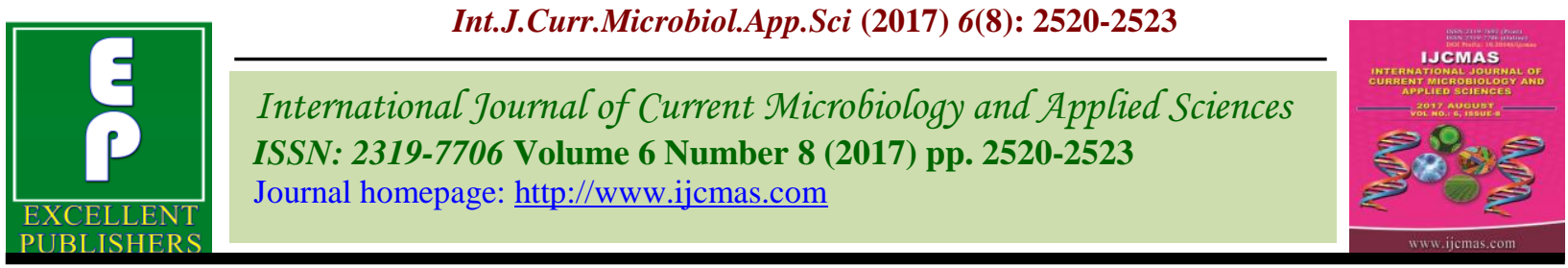

Original Research Article

https://doi.org/10.20546/ijcmas.2017.608.299

\title{
Management of Maize Weevil (Sitophilus zeamais) Using Different Grain Protectants
}

\author{
S.A. Hakeem, R.A. Wani* , B.A. Alie, S. Ansarul Haq, Seerat-u-Nissa, Sabiya Bashir, Fayaz \\ A. Bahar, Tanveer-ul-Hassan, Abrar Yaseen Baba, Aijaz A. Lone and F.A. Nehvi \\ Dry Land Agriculture Research Station, Budgam, SKUAST-Kashmir, J \& K, India \\ *Corresponding author
}

\section{A B S T R A C T}

Keywords

Maize, Stored

grain pest,

Sitophilus

zeamais and Grain

protectants.

Article Info

Accepted:

21 June 2017

Available Online:

10 August 2017
In order to evaluate the efficacy of certain grain protectants against Maize Weevil (Sitophilus zeamais; Curculionidae: Coleoptera), an experiment was conducted under laboratory conditions. Neem seed Kernel powder, Neem leaf powder, Inert Charcoal dust, Thiram, Custard apple seed powder, diflubenzuron, lufenuron, flufenoxuron, malathion, pared and dolomite were tested. Observations were recorded for the sex ratio and the number of emerged adults. In Inert dust, thiram, flufenoxuron and malathion treated kernels no adult emergence was observed and were followed by flufenoxuron, diflubenzuron and NSKP excepting pared in which the number of females and males were equal; in all the remaining treatments (in which adults emerged) the number of males was higher than females.

\section{Introduction}

Maize (Zea mays) one of the staple food crops of India is subjected to both quantitative and qualitative losses due to infestation by a number of insect species in field as well as in storage. In our country, post-harvest losses in Maize due to insect pests are particularly high and were reported to the extent of 20 per cent of the total harvest in coastal areas (Mookherjee et al., 1968). Smaller holdings and infrastructural bottlenecks limit the application of modern technologies in the storage of food grains in third world countries. Use of chemicals in grain storage to prevent from insect damages is an effective and easy way. However, the associated damagers of development of resistance in insects to these chemicals and residue hazards severely restrict their usage. On the other hand grain protectants such as physical toxicants, botanicals, Chitin synthesis inhibitors and other novel class of grain protectants not only inhibit insect infestation but also are free of residual hazards. Hence, in order to identify effective and safer grain protectants against the Maize weevil, Sitophilus zeamais which is an important species amongst the most destructive insect pests in the storage of Maize grains, the present experiment was conducted. Eleven grain protectants of diverse classes were tested for their ability in reducing the populations of Sitophilus zeamais. The results 
are presented and discussed in this contribution.

\section{Materials and Methods}

Three plant products viz. Neem leaf powder, Neem seed Kernel powder and Custard apple seed powder, two physical toxicants; Inert charcoal powder and Dolomite. Three insect growth regulators; Diflenoxuron, Flubenzuron and Lufenuron, one fungicide: Thiram, one Ayurvedic preparation; Pared and another insecticide Malathion were evaluated for their efficacy against Maize weevil (Sitophilus zeamais). Leaves and seed kernels of Neem and seeds of Custard apple were dried and ground to fine powder. The powder was passed through one $\mathrm{mm}$ mesh sieve. Eleven glass jars (500 ml capacity) were taken and each filled with Maize kernels up to its capacity. Required quantities of each grain protectants (Table 1) under testing were mixed thoroughly in the glass jars so that each grain receives uniform treatment. The treated seed material was stored in glass jars covered with a muslin cloth and fastened with an elastic band.

Fifty kernels from each treatment were taken in a glass tube $(20 \times 3 \mathrm{~cm})$, where in five pairs of one day old adult weevils of Sitophilus zeamais were released. The Weevils were allowed to remain inside the tubes for a period of ten days for the purpose of ovipositor and then were discarded. Observations were recorded on adult emergence and the sex ratio was calculated after 35 days. Untreated Kernels were served as control treatment. The experiment was replicated thrice. Resultant data was subjected to analysis of variance.

Approximately, $500 \mathrm{~g}$ of Maize Kernels in glass jars were moisture equilibrated in an incubator for a period of one week before infesting with 300 unsexed weevils (Miller et al.,; 1969). In order to obtain test insects of known or similar age, these weevils were allowed to ovipositor for seven days, after which they were removed from the infested grain using a mesh sieve. The infested Kernels were maintained at an ambient temperature of $30+5^{\circ} \mathrm{C}$ and $60+5^{\circ} \mathrm{C} \%$ relative humidity. The emerging adults were collected beginning from 30 days after post ovipositor period and the same were used in the experiment.

\section{Results and Discussion}

Maximum number of adults emerged in the control treatment followed by NLP and Dolomite. Flufenoxrn and Diflubenzuron were at par with each other and were significantly not different from the treatments. Inert charcoal dust, Thiram Lufenuron and Malathion in which no adults were emerged. Differences between Neem seed Kernel powder (NSKP) and Custard apple Seed powder (CASP), Neem seed Kernel powder and Flufenoxuron; CASP and Diflubenzuron and CASP and Pared were insignificant.

The number of females emerged in treatments Dolomite and NLP were significantly different from that of rest of the treatments. In case of number of males also maximum emergence was observed in control treatment followed by NLP and Dolomite. In treatments inert charcoal dust, Thiram, lufenuron and Malathion no males was observed. However, these treatments were significantly not different from NSKP, Flufenoxuron, Diflubenzuron and pared treatments which were at par with each other. In the treatments Custard apple seed powder CASP as compared to these four treatments more number of adults were emerged but the differences were not significant. Consequently sex ratio was zero in Inert charcoal powder, Thiram lufenuron and Malathion expecting pared in which it was one, sex ratio in the remaining treatments was less than one (Table 1). 
Table.1 Efficacy of grain protectants on adult emergence and sex ratio of Maize weevil Sitophilus zeamais

\begin{tabular}{|l|l|l|l|l|l|}
\hline \multicolumn{1}{|c|}{ Treatment } & Dosage(g.kg1) & \multicolumn{1}{|c|}{ A.E(+SD) } & Females(X+SD) & \multicolumn{1}{|c|}{ Males (X+SD) } & \multicolumn{1}{c|}{ Sex ratio } \\
\hline Dolomite & 5.0 & $5.67+0.47$ & $2.66+0.47$ & $3.00+0.81$ & $0.88: 1$ \\
\hline $\begin{array}{l}\text { Inert charcoal } \\
\text { dust }\end{array}$ & 5.0 & $0.00+0.00$ & $0.00+0.00$ & $0.00+0.00$ & $0.00+0.00$ \\
\hline $\begin{array}{l}\text { Neem leaf } \\
\text { powder }\end{array}$ & $2 \%$ & $12.33+2.05$ & $5.33+0.94$ & $7.00+2.16$ & $0.76: 1$ \\
\hline NSKP & $2 \%$ & $2.00+0.39$ & $0.66+0.47$ & $1.33+0.47$ & $0.49: 1$ \\
\hline CASP & $2 \%$ & $2.00+0.39$ & $0.66+0.47$ & $1.33+0.47$ & $0.49: 1$ \\
\hline Lufenuron & $0.5 \%$ & $0.00+0.00$ & $0.00+0.00$ & $0.00+0.00$ & 0 \\
\hline Flufenoxuron & 1.4 & $3.33+0.47$ & $0.00+0.00$ & $0.33+0.47$ & $0.0: 0.33$ \\
\hline Diflbenzuron & 0.4 & $1.33+0.47$ & $0.33+0.47$ & $1.00+0.47$ & $0.33: 33$ \\
\hline Parad & 4.0 & $3.33+1.24$ & $1.66+0.94$ & 1.6610 .47 & $1: 1$ \\
\hline Malathion & 3.0 & $0.00+0.00$ & $0.00+0.00$ & $0.00+0.00$ & 0 \\
\hline Control & & $20.33+1.69$ & $7.66+0.94$ & $12.66+1.69$ & $0.61 ; 1$ \\
\hline CD $(0.05)$ & & 1.91 & 1.12 & 1.84 & \\
\hline
\end{tabular}

The inert charcoal dust was found highly effective in suppressing the emergence of Sitophilus zeamais adults in Maize in the present investigation. In the present experiment among the Botanicals, NSKP and CASP were found well effective against Sitophilus zeamais. Earlier also few workers reported the insecticidal properties of custard apple seed against stored grain pests (Gondez Goana and Lagunes Tejeda,1986) The insecticidal properties of Custard apple seed were attributed to the presence of neoannoin (Kawazu et al.,1989), Significant difference in adult emergence of Maize weevil were observed between Neem leaf powder and seed powder. It was evident from the present results that NLP was less effective than NSKP as well as CASP also. No or negligeble adult emergence was observed in Kernels treated with IGRs. Similarly, Eisa and Ammar (1992) found complete control of Sitophilus oryza ini wheat grain with flufenoxuron. Parad tablet was found moderately effective in preventing the adult emergence in in Sitophilus zeamais. However, in this treatment Sex ratio was observed to be a favourable one (1:1) for the future build of Sitophilus zeamais population. Earlier Doharey and Agarwal (1989) found pared tablets at both the doses of 4 and 8 tablets of Sorghum grain effective in suppressing the populations of $S$. oryzae, Rhizopertha domnica, Trichogramma castaneum and T. granarium. The fungicide Thiram of S. oryzae, Rhizopertha domnica, Trichogramma castaneum and T. granarium. The fungicide Thiram was found to be more effective in controlling adult emergence Sitophilus zeamais. Thiram was reported to be effective against $S$. oryzae in Sorghum (Raghunathan et al., 1971) and S. cerealella in paddy (Sudheer Reddy and Hussaini, 1988). The efficiency of Thiram was attributed to one or more factors like antifeedent action or direct action by preventing breeding of insects. In addition, Thiram being sulphur containing compound there is also a possibility of fumigant action against the adults. However, its actual mode of action in suppressing the insect populations is not yet been delineated. Organophosphorus insecticide, Malathion has been found highly effective against Sitophilus zeamais. Malathion has lower mammalian toxicity, quick knock down effect and its use is widespread in grain storage. However, due to its excessive use and being a contact poison, 
important storage pests in India, viz., $T$. castaneum, Sitophilus oryzae, R. domnica and $O$. surinamensis have been reported to develop resistance to Malathion (Champ and Dyte,1976).Resistance in Sitophilus zeamais to Malathion has not been reported so far. Nevertheless, it is important to devise alternate management strategies involving inert materials such as inert charcoal dust. NSKP and Chitin synthesis inhibitor $\mathrm{s}$ which were found effective so as to reduce the dependence on Malathion and to ease the selection pressure in Sitophilus zeamaioz against Malathion to prevent any development of resistance as it happened in the case of storage insect pests.

\section{References}

Anonymous, 1973, 1973. Annual report of the Central plant Protection Institute, Hyderabad, 1972-1973.

Champ, B.R and Dyte, C.E. 1976. Report of the F A O global survey of pesticide susceptibility of stored grain pests, F A $\mathrm{O}$ Plant protection $\mathrm{J}$ and Protection series NO 5 F A O, Rome. Pp. 297.

Doharey, B.R and Agarwal, R.K. 1989. Studies on the parad tablets for the control of stored grain insect pests. Bull. Grain Tech., 27: 228-230

Eisa, A.A., and Ammar, I.M.A. 1992. Persistence of insect growth regulators against the Rice weevil, Sitophilus oryzae in grain commodities. Phytoparasitic, 20:7-13.
Gonzalez-Goana, O.J and Lagunes-Tegeda, A. 1986, A. 1986. Evaluation of technical and non-technical methods to control Spodoptera frugiperda and Spodoptera and Sitophilus zeamais in Lachontapatobasea, Mexico. Folia Entomologica Mexicio. Folia Entomolgicia Mexicana, 70:65-74.

Kawazu, K., alacantara, T.P and Kobayashi, A.1989. Isolation and structure of Neoannoin a novel insecticidial compound from the series of A. Squamosa Agric and Biol chem., 53:2719-2722.

Miller. A., philips, Land Cline, L.D.1969. Rearing manaual for stored product binsects used by USDA Stored product Insect research and development Laboratory, Savanah, Georgia, pp.36.

Mookherjee, P B., Jotwani, M.G., Sircar, P. And Yadav, T.D.1968. Studies on the incidence and extent of damage due to insect pests in stored seeds [-1 cereal seeds. Indian. J. Ent., 30:61-68.

Raghunathan, A.N., Ravindranath Gupta, M. And Majumdar, S.K. 1971. Effect of fungicide thiram on Sitophilus oryzae Mysore J. Agric. Sci. 5:487-489.

Sudheer Reddy, V and Hussaini, S.H. 1988. Studies on the pre-storage treatment on development of angoumoiis grain moth (Sitotroga cerealella oliver) in paddy. Proceedings of International conference of seed science and technology, held at New Delhi (Abst). pp 129.

\section{How to cite this article:}

Hakeem, S.A., R.A. Wani, B.A. Alie, S. Ansarul Haq, Seerat-u-Nissa, Sabiya Bashir, Fayaz A. Bahar, Tanveer-ul-Hassan, Abrar Yaseen Baba, Aijaz A. Lone and Nehvi, F.A. 2017. Management of Maize Weevil (Sitophilus zeamais) Using Different Grain Protectants. Int.J.Curr.Microbiol.App.Sci. 6(8): 2520-2523. doi: https://doi.org/10.20546/ijcmas.2017.608.299 